\title{
Citações presentes em teses e perfis de pesquisadores: fontes de indícios para se estudar a área da educação física
}

Ivone Job

\section{Bibliotecária da Escola de Educação Física da UFRGS Mestre em Ciência da Informação pela ECI/UFMG}

\section{Lídia Alvarenga}

\section{Professora Doutora da Escola de Ciência da Informação da UFMG}

Análise de perfis de 16 professores e 1.171 citações de teses do Programa de Pós-graduação em Ciências do Movimento Humano (PPGCMH) da Escola de Educação Física (EsEF) da Universidade Federal do Rio Grande do Sul (UFRGS), defendidas nos anos de 2003 e 2004, com os objetivos de: detectar as características das fontes de informação utilizadas pelos doutores; contribuir para aos estudos epistemológicos do campo; caracterizar elementos textuais e explorar suas potencialidades, visando ao conhecimento do campo científico da educação física. Análises empíricas de citações e dados dos perfis originaram indícios para atingir os resultados que evidenciaram traços de interdisciplinaridade e, juntamente com outras variáveis empíricas levantadas, podem se constituir em insumos para análises e interpretações futuras por parte dos pesquisadores da comunidade estudada.

Palavras-chave: Análise de citações; Educação física; Método indiciário; Escola de Educação Física da Universidade Federal do Rio Grande do Sul (UFRGS). 


\section{Thesis citations and researchers' profiles: clues for studying the physical education area}

This is an analysis of profiles of 16 professors and 1.171 quotations from theses produced at the PPGCMH (Graduate Program on Human Movement Science) at the EsEFUFRGS (Physical Education College/Federal University of RS) in 2003 and 2004. The objectives were: to determine the features of the sources of information used by these professors; to contribute for the epistemological studies in the field from the Information Science perspective; to describe textual elements and explore their potentialities in an attempt to improve the knowledge about the scientific field of physical education. Empirical analyses on the quotations and the profile data created lines of study in the field. The results revealed clear characteristics of interdisciplinarity in the specific area of knowledge, which, along with other empirical variables found, can turn into elements that may encourage future analyses and interpretations taken by researchers belonging to the community studied.

Keywords: Citation analysis; Physical education; Cluefollowing method; Escola de Educação Física da Universidade Federal do Rio Grande do Sul - UFRGS.

Recebido em 01.01.2008 Aceito em 13.10.2008

\section{Introdução}

Para o estudo ora apresentado, sobre a pesquisa no campo da educação física, partiu-se do pressuposto de que as análises dos perfis dos professores e das citações constantes de teses podem possibilitar o levantamento de importantes variáveis, tais como autores mais citados, assuntos predominantes, fontes mais utilizadas pelos doutores e outras, de forma a se levantar indícios sobre a estrutura e o comportamento da área. Também informações extraídas dos perfis dos pesquisadores foram consideradas igualmente contribuidoras. Ressaltou-se, sobretudo, que a antevisão da ocorrência, no campo estudado, de empréstimos de outros campos fronteiriços do conhecimento não é fato de se estranhar na atualidade, tal como ocorre na ciência da informação. O conhecimento da área da educação física, ao dialogar e interagir com outras disciplinas, 
replicaria uma tendência presente em outras ciências emergentes, surgidas na segunda década do século XX.

A escolha da análise de alguns elementos relativos a teses produzidas pela comunidade da educação física, acrescida do estudo dos perfis dos pesquisadores da mesma comunidade, para se conhecer o estado e as tendências da área, justifica-se por considerar esse tipo de publicação como produto relevante da pesquisa acadêmica, responsável pelos reflexos da pesquisa em andamento e vetor de influência para as próximas gerações de pesquisadores do campo de conhecimento.

Meadows (1999) relata que o padrão de educação tem se elevado de modo significativo durante o último século, inclusive nos níveis de pósgraduação:

Considerando que são pessoas com doutorado que, certamente, formarão a próxima geração de pesquisadores, esse crescimento reveste-se de importância para a comunidade científica. [...] A essa velocidade de produção de pesquisadores, o edifício da ciência eleva-se de uma casa para um arranha-céu, diante de nossos olhos. Para um membro da comunidade científica a conseqüência imediata dessa expansão é que a maior parte dos pesquisadores é formada de contemporâneos. [...] Temos hoje o privilégio de sentarmos ao lado dos 'gigantes sobre cujos ombros nos apoiamos' (MEADOWS, 1999, p. 15).

Os perfis dos 16 professores doutores foram analisados em detalhes, com o objetivo de se conhecer as características dos pesquisadores do Programa de Pós-Graduação em Ciências do Movimento Humano, PPGCMH: sua formação acadêmica, as linhas de pesquisas a que se encontram vinculados e como elas se apresentam no programa, as disciplinas que concorreram para a formação acadêmica dessas pessoas, assim como os objetos e as temáticas dos grupos de pesquisa.

Por outro lado, as teses defendidas no doutorado PPGCMH da ESEF da UFRGS foram também focalizadas em sua totalidade, no presente estudo, por vários motivos: ter o doutorado início recente (no ano de 1989 o mestrado e em 2000 o doutorado); por se tratar de uma área do conhecimento ainda a ser explorada por estudos bibliométricos; e ser uma comunidade que propicia a análise de tendências de pesquisa dentro da área da educação física.

\section{Estudos bibliométricos}

Encontram-se na literatura várias denominações para tais estudos, tais como livrometria, webmetria, cientometria, bibliometria, infometria ou informetria. 
Para Sengupta (1992), os termos bibliometria, informetria, cientometria e livrometria são derivados da fusão dos termos "métrica" com bibliografia, informação, ciência e biblioteca respectivamente. Os termos são análogos ou quase sinônimos, mas, na verdade, expressam diferentes aplicações, envolvendo diferentes fontes e aspectos relativos a campos disciplinares focalizados, que têm sido objeto de estudos e pesquisas na ciência da informação e da biblioteca. Todos esses termos estão relacionados diretamente com medidas do conhecimento publicado, decorrente de novas idéias veiculadas pelos canais de comunicação científica.

Sobre a presença e a inserção desse tipo de estudo no campo teórico-metodológico da Ciência da Informação, ressaltam-se alguns motivos, dentre outros: por serem as unidades de informação espaços privilegiados do referido campo, responsáveis pelo armazenamento e disseminação de informações e documentos relativos aos saberes de todas as áreas, sejam estes científicos ou não científicos; por serem os pesquisadores dessa área os profissionais que tendem a ser, pela sua formação, mais aptos para acessar conjuntos representativos de documentos e para planejar e analisar variáveis que evidenciem aspectos do comportamento da literatura; por se constituir, enfim, a Ciência da Informação, um campo onde se organizam e disponibilizam dados que contribuem para se aprofundar o conhecimento da comunicação científica entre os autores/pesquisadores.

Fonseca (1979) afirma que as análises bibliométricas possuem também o objetivo de comprovação ou retificação da história das idéias, tanto pelo relacionamento entre documentos citados e documentos citantes, como pelo recenseamento ideográfico de bibliografias nacionais. A análise de citações que constam dos textos científicos são apenas um dos tipos dessas análises.

Muitos são os trabalhos desenvolvidos no campo da Ciência da Informação no Brasil com base em análise de citações, conceito já bastante explorado, com vasta literatura publicada. Considera-se importante ressaltar, neste trabalho, o fato de possuírem as citações elementos que podem ser vistos como indícios para esclarecimento sobre um campo de conhecimento, a partir de sua literatura.

Refletindo sobre as citações, levanta-se a questão: por que citar? Uma explicação provável nos é dada por Burke (2003), que situa nos primórdios do século XVII, início da ciência moderna, com questões conflituosas de ceticismo, as explicações até então dadas aos fenômenos naturais, um marco para a introdução da citação das fontes nos textos históricos. A importância atribuída ao particular, ao detalhe, à quantificação e ao conhecimento imparcial, características da ciência moderna, levou à prática, entre os historiadores, de orientar o leitor a verificar a evidência ou ter informações adicionais sobre o que estava sendo afirmado, através da nota ao pé da página, ao lado da página ou nas suas margens. Esta informação tinha como objetivo principal, segundo Burke: 
[...] facilitar um retorno às 'fontes', seguindo o princípio de que a informação, como a água, era mais pura quanto mais próxima estivesse da fonte. A nota histórica, como a descrição detalhada de um experimento, pretendia permitir que o leitor pudesse repetir a experiência do autor se assim o desejasse (BURKE, 2003, p. 185).

Nos meios científicos, a prática de citar as publicações que serviram de base para a produção de um trabalho pode ser vista como um dos imperativos do método científico, embora sejam apresentados também fatores limitantes desse comportamento.

Apesar da grande importância da citação na comunicação científica atual, Demo (1985, p.40) afirma que "[...] a citação não é autoridade, porquanto é somente instrumental. Um trabalho sem citação pode ser tão científico quanto outro abarrotado delas. Um trabalho sem citação é apenas mais pobre em referência à discussão circundante do tema". O autor critica o exagero e as intenções de que são acometidos alguns autores ao citar, tais como mostrar erudição, citar os mais importantes, etc. Ele atribui valor à citação no sentido de permitir ao leitor refazer, criticamente, o roteiro da construção científica seguido pelo autor. Mas, é exatamente este o sentido da origem das citações, o de refazer 0 "roteiro". Mesmo tendo que concordar com sua crítica a respeito do abuso das citações, não há como imaginar que alguém escreva algo tão puro e original que não tenha se apoiado em ninguém.

\section{Procedimentos Metodológicos}

A metodologia utilizada no presente estudo compreende três partes: a) levantamento dos perfis dos pesquisadores; b) levantamento das citações constantes das teses de doutorado defendidas no PPGCMH/UFRGS, segundo algumas variáveis; c) análise dos indícios encontrados em a) e b) com a finalidade de propiciar a visão do campo de conhecimento.

Os dados para a obtenção do perfil dos professores da PPGCMH da EsEF foram coletados através de um questionário enviado a eles, em meados de 2005, tendo como base a lista fornecida pela secretaria do PPGCMH. O questionário foi respondido por 13 dos 16 professores do quadro. Para complementar as informações sobre os grupos de pesquisa e formação acadêmica, buscou-se o sitio do CNPq, o Currículo Lattes e o Diretório de Grupos de Pesquisa no Brasil. Este diretório relaciona os grupos de pesquisa que foram certificados pelos dirigentes institucionais das instituições participantes e as informações atualizadas nos últimos 12 meses.

Por outro lado, foram analisadas 1.171 citações constantes das teses defendidas em 2003 e 2004. Optou-se por analisar todos os trabalhos defendidos desde a criação do doutorado no PPGCMH da EsEF da UFRGS, pressupondo-se que, ao se analisar a totalidade da produção de 
uma determinada comunidade científica, haveria maior probabilidade de se observar suas características originais e suas tendências.

As variáveis analisadas foram: autoria (tipo de autores e autores mais citados), data de publicação, tipologia documental, idioma, títulos dos periódicos mais citados e assuntos das citações.

Os elementos extraídos de ambas as fontes foram considerados neste trabalho como indícios, pistas, ou, como denominou Ginzburg (2003), os fios que compõem um tapete formado de uma trama densa e significativa. O tapete seria o paradigma da área encontrado que, conforme 0 contexto indiciário, pode ser denominado semiótico ou divinatório. O investigador divide com os membros da comunidade 0 papel de tecelão ao tentar, a partir dos indícios, reunir informações, praticando uma interpretação que encontra maior significado se calcada em um determinado contexto histórico.

As citações como indícios, sinais, sintomas não são novidade na ciência da informação. Cronin, em 1984, afirmava que:

[...] num mundo ideal, citações devem ser tidas como marcas ou símbolos objetivos, devem ser vistas como empregadas de modo consistente e devem ser suscetíveis a análises e interpretações consistentes. As citações bibliográficas têm sido descritas como símbolos, marcas, metáforas e sinais (CRONIN,1984, p. 68-69).

As citações atuam como sinais, estabelecem relações com o passado e o presente, através de seus elementos - quem escreveu, onde, em que idioma, quando, em que local -, para assim dar continuidade ao saber humano, deixando as marcas da produção intelectual. As variáveis da análise de citações seriam, usando a metáfora de Ginzburg (2003), os fios do tapete que representam uma realidade, um campo de conhecimento.

Freire $(2003$, p.53) utilizou o método para "[...] caçar na literatura da ciência da informação, os indícios de uma visão do mundo em que a informação científica e tecnológica é considerada em si mesma, uma força produtiva e fator de transformação social". Ginzburg (2003) usa a metáfora do caçador por entender que este foi o primeiro homem a narrar a história, porque era o único capaz de ler, nas pistas mudas, uma série coerente de eventos.

Araújo (2005) propõe o paradigma indiciário como base metodológica do fazer científico, na epistemologia da ciência da informação, através da intuição (empírica e racional). A autora considera esgotada a forma clássica de ver a ciência moderna e incapaz de fazer avançar os empreendimentos metodológicos necessários às novas áreas de conhecimento, "[...] que devem trabalhar com a razão e a emoção centradas na capacidade humana de gerar conhecimentos" (ARAúJO, 2005, p. 8). 
A adoção da abordagem indiciária a partir da análise de citações, neste trabalho, respalda-se em seu objetivo mais amplo de tentar detectar na literatura elementos significativos como indícios importantes para a constituição, a história e o estado de conhecimento do campo da educação física. No âmbito do PPGCMH, a análise de citações e o perfil de pesquisadores podem auxiliar na caracterização do conhecimento e no levantamento de possíveis indicadores de novos rumos para as pesquisas, no caso, no doutorado.

\section{Resultados}

\subsection{Perfil dos professores/pesquisadores}

O perfil dos professores do PPGCMH foi analisado quanto aos seguintes aspectos: formação acadêmica (cursos realizados na graduação e pós-graduação); linhas de pesquisas a que se acham vinculados e como elas se apresentam no programa; os grupos de pesquisas vinculados aos pesquisadores do PPGCMH; e as disciplinas que são ministradas e suas temáticas.

Quanto à formação dos pesquisadores, obteve-se o seguinte resultado: na graduação, $82 \%$ dos professores possuem licenciatura em educação física e $18 \%$ em outras áreas. Em nível de especialização, o quadro é bastante heterogêneo, com destaque para os cursos ligados ao esporte $(64 \%)$. O mestrado, em sua maioria, foi realizado no país $(73 \%)$, com um quadro de cursos também bastante heterogêneo, mas com uma leve vantagem para a área de educação (26\%). Para o doutorado, $75 \%$ dos professores buscaram instituições no exterior, com predominância nos Estados Unidos e Canadá, em áreas diversas, com uma leve predominância de cursos ligados ao esporte (26\%).

Observou-se a predominância das linhas de pesquisas no PPGCMH de atividade física e performance (31\%) e atividade física e saúde $(26 \%)$. Juntas, representam $57 \%$, revelando a predominância de projetos de pesquisa relacionados ao movimento humano, seus efeitos preventivos; de reabilitação de doenças, com aprendizagem, treinamento e performance motora. A linha de pesquisa denominada formação de professores e prática pedagógica é a de menor representação, com 4\%. Portanto, a área de concentração Movimento humano, saúde e performance representa $79 \%$ das linhas de pesquisas, e a área Movimento humano, cultura e educação, $21 \%$.

Apesar de não constar nas teses a informação sobre a qual linha de pesquisa pertencem, observa-se pela linha dos orientadores que $89 \%$ das teses defendidas no PPGCMH revelam predominância de pesquisa na área de movimento humano, saúde e performance, e $11 \%$ pertencem à área movimento humano, cultura e educação. Isso leva a crer que a área de movimento humano, saúde e performance é a preferida pelos candidatos ao doutorado ou, pelo fato de possuir mais professores orientadores, temse maior atendimento a projetos de pesquisa desta linha. 
Um conjunto de dez professores do PPGCMH (62\%) participa de grupos de pesquisa cadastrados no CNPq, evidenciando continuidade de estudos de reforço e aprimoramento do grupo nas pesquisas.

\subsection{Análise de citações segundo as variáveis consideradas}

No estudo de elementos dos trabalhos citados evidenciaram-se os seguintes resultados:

\subsubsection{Autoria}

Todos os autores constantes das citações foram contabilizados. A TAB. 1 apresenta os tipos de autoria dos documentos, divididos em autoria única (somente um autor), múltipla (mais de um autor) e institucional. Sem autor refere-se, principalmente, às revistas de divulgação. Verifica-se que, num total de 1.171 citações, 54\% são de autoria múltipla, $42 \%$ são de autoria única, 3\% de autoria institucional.

TABELA 1 - Tipo de autoria do documento

\begin{tabular}{l|c|c}
\hline \multicolumn{1}{c|}{ Tipo de autoria } & Freqüência citações & \% citações \\
\hline \hline Sem autor & 8 & 0,7 \\
\hline Institucional & 39 & 3,3 \\
\hline Única & 489 & 41,8 \\
\hline Múltipla & 635 & 54,2 \\
\hline TOTAL & $\mathbf{1 . 1 7 1}$ & $\mathbf{1 0 0}$ \\
\hline
\end{tabular}

Fonte: Dados da pesquisa.

A educação física, como um campo interdisciplinar, apresenta índices similares para a autoria múltipla $(54,2)$ e autoria única $(41,8)$. Provavelmente por ter vínculos tanto com a área das ciências da saúde, cuja característica nos textos é a autoria múltipla, quanto com a das ciências sociais e humanidades, que tem como característica a autoria única.

Os resultados mostram a inexistência de um grupo de autores fortemente citados, já que $80,71 \%$ deles foram citados somente uma vez num total de 1.825 diferentes autores.

A inexistência de um grupo de autores mais citados pode revelar a dispersão das disciplinas e conseqüentemente do conhecimento produzido. A educação física está dispersa em várias áreas, como já foi visto pelas disciplinas que envolvem as linhas de pesquisas do PPGCMH, e está em busca de sua legitimidade acadêmica e de um referencial teórico que a consagre como ciência. Afinal, sua presença acadêmica é recente, jovem ainda no Brasil, com cerca de 30 anos de pós-graduação, data marcada pela defesa da primeira dissertação em educação física no Brasil, na USP em 1979. 
Foram considerados representativos, neste estudo, autores citados no maior número de teses. Turner, C.H. e Henderson, S.E., os dois primeiros colocados, são particulares de uma disciplina e foram citados em somente uma tese. Portanto, destacam-se nas citações da comunidade analisada os seguintes autores: Edgar Morin, (quatro teses) Anne Lapierre e Michael Foucault (três teses). Este resultado leva a crer que no referencial da produção científica desta comunidade há algum indício da influência de construtos teóricos da escola francesa, marcadamente, de Edgar Morin, autor com forte presença no Brasil e em estudos transdisciplinares.

\subsubsection{Data de publicação}

A data de publicação é a variável que verifica o período cronológico em que são publicados os documentos citados. De maneira geral, estudos mostram que as disciplinas da área social e de humanidades têm como característica utilizar documentos clássicos, e as das áreas médica e tecnológica buscam seu referencial em documentos recentes (MEADOWS, 1999).

NO GRÁF. 1 observa-se a distribuição dos documentos citados na década de 90 e nos anos de 2000 a 2004, em que se evidencia o ano de 1998 como o mais citado:

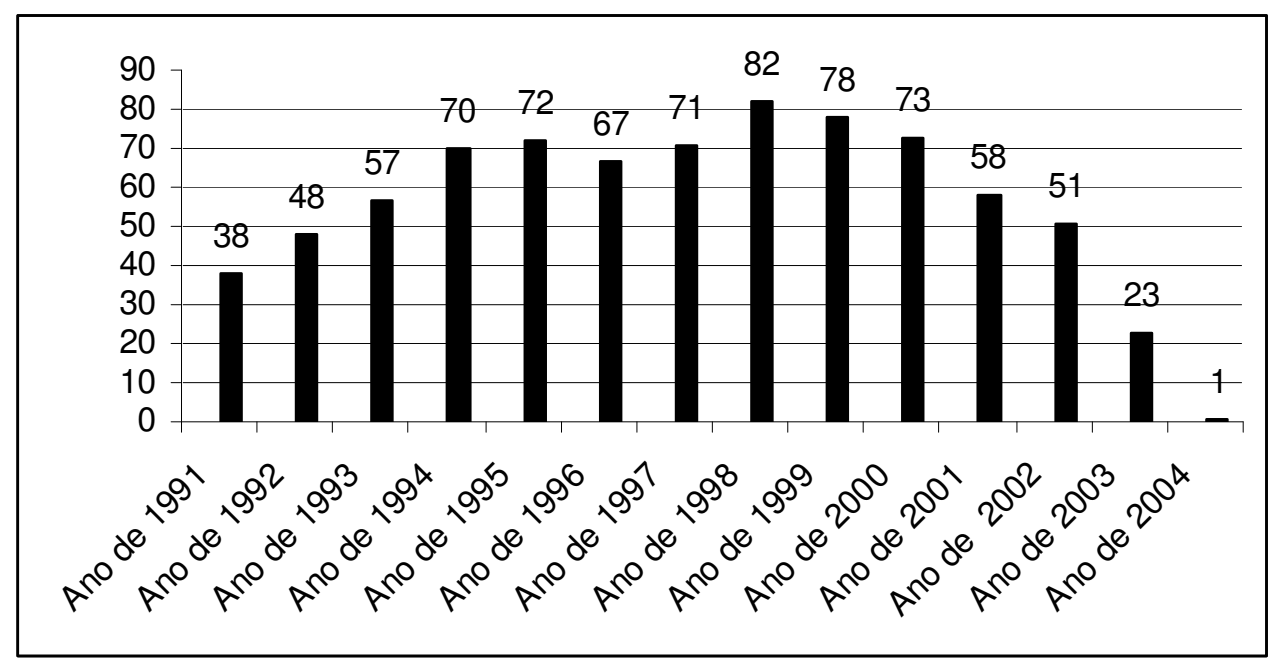
a 2004.

GRÁFICO 1 - Gráfico das citações referentes aos anos de 1991

Fonte: Dados da pesquisa.

As publicações da década de 90 (1991-2000) significam $56 \%$ do total, com 656 citações. Esta data corresponde ao ano da edição de uma obra, seja ela uma tradução ou uma reedição.

Observa-se que o ano de 1998 obteve um pico dentro desta década. Como as teses foram defendidas nos anos de 2003 e 2004, supõe-se que a maior quantidade de literatura na área de educação física tem a meia- 
vida em torno de cinco a seis anos, obedecendo-se à "curva de declínio de citações" utilizada por Meadows (1999). Esse valor depende da área a ser analisada e, salienta Meadows (1999), o mais importante neste tipo de avaliação é revelar os hábitos de literatura de diferentes campos do conhecimento.

\subsubsection{Tipologia documental}

Observou-se que artigo de periódico estrangeiro perfaz quase a metade das citações $(45,5 \%)$, confirmando a preferência dos pesquisadores para este tipo de material. Incluindo-se os artigos de periódicos nacionais $(4,1 \%)$, totaliza $49,6 \%$ das citações a artigos de periódicos. A escolha por periódicos editados fora do país pode revelar a ausência de pesquisas nacionais recentes sobre os temas apresentados nas teses, maior confiança nesse tipo de documento produzido no exterior, ou a falta de revistas científicas brasileiras para escoar a produção nacional da área.

TABELA 2 - Freqüência por tipo de documento

\begin{tabular}{l|c|c}
\multicolumn{1}{c|}{ Tipo de documento } & Freqüência das citações & \% das citações \\
\hline \hline Artigo de Periódico Estrangeiro & 532 & 45,5 \\
\hline Livro e capítulo de livro Nacional & 312 & 26,6 \\
\hline Livro e capítulo de livro Estrangeiro & 185 & 15,8 \\
\hline Artigo de Periódico Nacional & 48 & 4,1 \\
\hline Dissertação/Tese & 31 & 2,6 \\
\hline Comunicação em Evento Nacional & 19 & 1,6 \\
\hline Artigos de revistas e jornais de divulgação & 16 & 1,0 \\
\hline Documento Eletrônico & 12 & 0,8 \\
\hline Outras Publicações & 9 & 0,6 \\
\hline Comunicação em Evento Estrangeiro & 7 & $\mathbf{1 0 0}$ \\
\hline TOTAL & $\mathbf{1 . 1 7 1}$ & \\
\hline
\end{tabular}

Fonte: Dados da pesquisa.

O mesmo comportamento não se observa em relação aos livros, sendo a preferência por aqueles editados no Brasil (26,6\%). Incluem-se nesta categoria os livros traduzidos, como por exemplo os citados de Michel Foucault, Vygotsky, Morin, Bacon, Bohr, Capra, Descartes, Eco, Lapierre, Piaget e outros, revelando tentativas de fundamentação teóricometodológica em autores consagrados por parte da comunidade científica estudada.

Observou-se o pouco uso das teses e dissertações como material de ponta para as pesquisas $(2,6 \%)$, mesmo para as defendidas no PPGCMH, apesar de estarem disponíveis full text em meio eletrônico. Isso pode demonstrar pouca coesão entre os trabalhos desenvolvidos no PPGCMH ou desconhecimento da importância deste tipo de documento. 


\subsubsection{Idioma}

Quanto ao idioma dos documentos citados, a predominância é do inglês, com $55 \%$, seguido do idioma português, com $40 \%$, totalizando juntos $95 \%$ das citações.

A preferência pelo uso do idioma inglês coincide com a preferência por tipos de documentos. Provavelmente, os artigos de periódicos estrangeiros, que atingiram $45 \%$, sejam na sua maioria neste idioma.

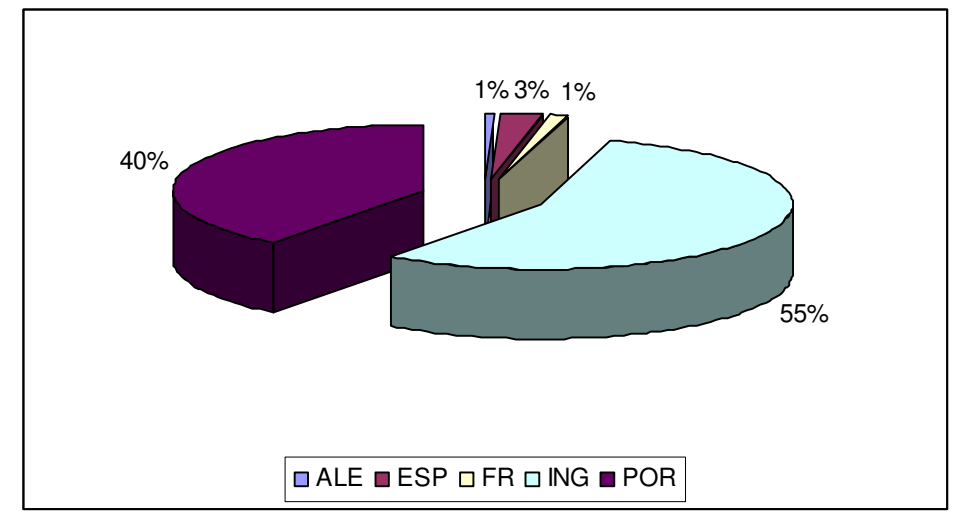

GRÁFICO 2 - Gráfico de distribuição das citações por idioma.

Fonte: Dados da pesquisa.

A língua portuguesa foi provavelmente a preferida para os livros, já que obteve na tipologia em livro e capítulo de livros o índice de $26 \%$. A preferência pela leitura de livros em português inclui autores nacionais e traduções, e também os editados em Portugal.

\subsubsection{Periódicos citados}

As 580 citações de periódicos nacionais e estrangeiros foram feitas em um total de 257 periódicos. Foi considerado um núcleo de periódicos mais citados com os que receberam as 15 maiores pontuações de citação nas teses do PPGCMH. Observa-se a inclusão de somente um periódico nacional, a revista Movimento, produzido e editado pela instituição em foco neste estudo. Os demais são: Journal of Applied Physiology, The Journal of Physiology, Medicine and Science in Sports and Exercise, Journal of Biomechanics e European Journal of Applied Physiology.

\subsubsection{Assunto}

A variável assunto foi contemplada tanto no perfil dos professores quanto na análise de citações. Para obter-se consistência dos termos encontrados, utilizou-se o tesauro do Sport Discus, (INFORMATION...,1987). Para a enumeração das disciplinas nas tabelas, optou-se por usar o termo mais amplo do tesauro, considerando-se a necessidade de identificação do campo de conhecimento correspondente. 
Por exemplo, ao procurar o termo biomecânica no tesauro aparece a seguinte estrutura:

Subject: biomechanics. Broader term: BIOPHYSICS.

$O$ resultado do levantamento de disciplinas no perfil dos professores forneceu os termos da TAB. 3 a seguir:

TABELA 3- Levantamento de disciplinas no perfil dos professores

\begin{tabular}{|c|c|c|}
\hline Assunto & Freqüência & $\%$ \\
\hline Psicologia (ciências sociais) & 6 & 14,62 \\
\hline Esporte (esporte) & 5 & 12,20 \\
\hline Ensino (ensino) & 4 & 9,76 \\
\hline Medicina (medicina) & 4 & 9,76 \\
\hline Biomecânica (biofísica) & 3 & 7,32 \\
\hline Educação (educação) & 3 & 7,32 \\
\hline Fisiologia (medicina) & 2 & 4,87 \\
\hline Metodologia (ciência) & 2 & 4,87 \\
\hline Administração (administração) & 1 & 2,44 \\
\hline Anatomia (biologia) & 1 & 2,44 \\
\hline Atividades físicas (forma física) & 1 & 2,44 \\
\hline Bioquímica (ciência) & 1 & 2,44 \\
\hline Cognição (psicologia) & 1 & 2,44 \\
\hline Filosofia (filosofia) & 1 & 2,44 \\
\hline Olimpismo (filosofia) & 1 & 2,44 \\
\hline Percepção (psicologia) & 1 & 2,44 \\
\hline Performance psicomotora (psicologia) & 1 & 2,44 \\
\hline Recreação (recreação) & 1 & 2,44 \\
\hline Sociologia (ciências sociais) & 1 & 2,44 \\
\hline Treino (esporte) & 1 & 2,44 \\
\hline TOTAL & 41 & 100 \\
\hline
\end{tabular}

Fonte: Dados da pesquisa.

Os descritores que estão entre parênteses significam o termo mais amplo. Assim, na área de ciências sociais temos os seguintes descritores: sociologia e psicologia (24,38\%), que por sua vez abrange percepção, cognição e performance motora. No esporte estão contidas todas as modalidades do esporte, que não foram descriminadas nesta tabela por serem bastante extensas, mais o termo treino (ou treinamento). Na grande área da medicina está incluído o descritor fisiologia. O assunto biomecânica é um descritor da área de biofísica. Na filosofia está contido o descritor olimpismo. Na grande área de ciência estão contidos os descritores metodologia científica e bioquímica, ficando desta forma as 
seguintes grandes áreas: ciências sociais (psicologia + sociologia) com 24,38\%; esporte com 14,64\%; medicina com 14,63\%; ensino com $9,76 \%$; biofísica, ciência e educação com $7,32 \%$ cada uma; filosofia com 4,88\%; administração, recreação, forma física e biologia, com 2,44\% cada uma.

Na análise das citações, a variável assunto obteve um conjunto de 621 descritores que foram utilizados de 10 a 59 vezes $(53,03 \%)$. Os demais $(46,97 \%)$ foram citados de uma a nove vezes, sendo que 112 $(9,6 \%)$ descritores o foram somente uma vez.

A análise dos assuntos das citações revela as temáticas predominantes que os autores das teses utilizaram para realizarem seus estudos e visa detectar as disciplinas envolvidas na área de educação física, sendo que se apresentam com mais disciplinas do que as encontradas no perfil de professores.

TABELA 4- Levantamento das disciplinas da análise de citações.

\begin{tabular}{|c|c|c|c|}
\hline $\begin{array}{c}\text { Freqüência } \\
\text { unitária }\end{array}$ & Descritores & $\begin{array}{c}\text { Freqüência } \\
\text { total }\end{array}$ & $\%$ \\
\hline 59 & Biomecânica (biomechanics) & 59 & 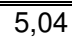 \\
\hline 55 & Coordenação motora (coordination) & 55 & 4,70 \\
\hline 46 & Filosofia (philosophy) & 46 & 3,93 \\
\hline 38 & Atividade física (exercise) & 38 & 3,25 \\
\hline 31 & Disfunção motora (motor disorder) & 31 & 2,56 \\
\hline 30 & Educação física (physical education) & 30 & 2,65 \\
\hline 26 & Saúde: educação (health education) & 26 & 2,22 \\
\hline \multirow[t]{2}{*}{21} & Doença (disease); educação especial (special education) e & 63 & 5,38 \\
\hline & eletromiografia (electromyography) & & \\
\hline 20 & Corporeidade (body awareness) & 20 & 1,71 \\
\hline \multirow[t]{2}{*}{18} & Desenvolvimento motor (motor development); Força muscular & 54 & 4,61 \\
\hline & (power) e Ortopedia (orthopedics) & & \\
\hline \multirow[t]{2}{*}{17} & Bioética (ethics + biology); Placa de crescimento (growth plate) & 51 & 4,36 \\
\hline & e Postura Corporal (posture) & & \\
\hline 16 & Ética (ethics); Tabagismo (smoking) & 32 & 2,73 \\
\hline 15 & Psicomotricidade (psychomotor performance) & 15 & 1,28 \\
\hline 13 & Epistemologia (epistemology); Habilidade motora (Motor skill) & 26 & 2,22 \\
\hline 12 & Dieta alimentar (diet); moral (moral development) & 24 & 2,05 \\
\hline 11 & Crescimento (body development) & 11 & 0,94 \\
\hline \multirow[t]{2}{*}{10} & Composição corporal (body composition); Obesidade (obesity); & 40 & 3,42 \\
\hline & Psicologia infantil (child:psychology) e Sociologia (sociology) & & \\
\hline 9 & 6 descritores & 54 & 4,61 \\
\hline 8 & 3 descritores & 24 & 2,05 \\
\hline 7 & 7 descritores & 49 & 4,18 \\
\hline 6 & 10 descritores & 60 & 5,12 \\
\hline 5 & 9 descritores & 45 & 3,84 \\
\hline 4 & 14 descritores & 56 & 4,78 \\
\hline 3 & 20 descritores & 60 & 5,12 \\
\hline 2 & 45 descritores & 90 & 7,69 \\
\hline 1 & 112 descritores & 112 & 9,56 \\
\hline Total & & 1171 & 100 \\
\hline
\end{tabular}

Fonte: Dados da pesquisa. 
A partir das informações sobre o assunto das teses e do perfil de professores, obtém-se a TAB. 5.

TABELA 5 - Dados comparativos entre os descritores obtidos no perfil dos professores e na análise de citações

\begin{tabular}{l|c|c|c}
\hline Descritores & Análise de citações & Perfil & Total \\
\hline \hline Ciências sociais & 14,41 & 24,38 & 38,79 \\
\hline Medicina & 10,07 & 14,63 & 24,70 \\
\hline Biofísica & 8,28 & 7,32 & 15,60 \\
\hline Esportes & 0 & 14,64 & 14,64 \\
\hline Educação & 6,58 & 7,32 & 13,90 \\
\hline Filosofia & 7,44 & 4,88 & 12,32 \\
\hline Ensino & 0 & 9,76 & 9,76 \\
\hline Forma física & 6,24 & 2,44 & 8,68 \\
\hline Ciência & 0 & 7,32 & 7,32 \\
\hline Administração & 0 & 2,44 & 2,44 \\
\hline Biologia & 0 & 2,44 & 2,44 \\
\hline Recreação & 0 & 2,44 & 2,44 \\
\hline
\end{tabular}

Fonte: Dados da pesquisa.

Observam-se as grandes áreas que fazem a interdisciplinaridade da Educação Física, segundo o estudo das teses do PPGCMH da EsEF da UFRGS: ciências sociais, medicina, biofísica, esportes, educação, filosofia, ensino e forma física. Demais disciplinas obtiveram percentagens menores, mas que marcam sua presença no campo analisado.

\section{Considerações finais}

Realizado o levantamento dos indícios, os investigadores da presente pesquisa somente iniciam o processo de interpretação $e$, sobretudo, convidam os pesquisadores da área, os tecelões, para comparar as variáveis identificadas tal como fios para se tecer o tapete que representaria o campo analisado. Nesse processo também concorrem certamente interpretações envolvendo o contexto de produção do conhecimento.

As particularidades apontadas neste estudo, que teve como dados empíricos o perfil dos professores e as citações das teses do PPGCMH, permitiram levantar insumos valiosos para análises posteriores que poderão ser desenvolvidas pela própria comunidade analisada:

Considera-se um dado relevante obtido na pesquisa a inexistência de citações de documentos que tratam da medicina do esporte nas pesquisas do PPGCMH. A medicina do esporte foi origem e propulsora das pesquisas na comunidade da EsEF, através do Laboratório de Pesquisa do exercício (LAPEX). Hoje a medicina do esporte não exerce mais este papel determinante na instituição analisada. 
O estudo, em geral, confirmou a necessidade de maior produção nacional em termos teóricos para a área de educação física. Inclusive, esta denominação aparece em poucas disciplinas do currículo de pósgraduação, sendo substituída por movimento humano.

A análise realizada propiciou verificar que os campos científicos e as suas respectivas comunidades se desenvolvem de forma contingencial e contextual. O método indiciário possibilitou costurar os indícios apresentados pelas variáveis analisadas e mostrou ser um método possível em estudos de bibliometria e análise de citações. Há indícios de hábitos de citação doméstica e endogenia, mas não foram comprovados neste estudo.

A busca pela caracterização das conexões, tanto intertextuais como interdisciplinares, no perfil dos professores e nas citações das teses da comunidade de doutores da EsEF, permitiu a esta investigadora apostar no método indiciário e na pertinência dos indícios apresentados. Ao explorar a superfície da qual emergem os elementos das citações das teses, acredita-se ter achado novos elementos que vão colaborar com o desenvolvimento do campo de conhecimento da educação física e da ciência da informação.

\section{Referências}

ARAÚJO, E. A. Por uma ciência formativa e indiciária: proposta epistemológica para a ciência da informação. In: ENCONTRO NACIONAL DE PESQUISA EM CIÊNCIA DA INFORMAÇÃO (ENANCIB), 6., 2005. Florianópolis. Anais... Florianópolis: ANCIB, 2005. 1 CD-ROM.

BURKE, P. Uma história social do conhecimento: de Gutenberg a Diderot. Rio de Janeiro: Zahar, 2003.

CRONIN, B. The citation process. London: Taylor Graham, 1984.

DEMO, P. Introdução à metodologia da ciência. 2. ed. São Paulo: Atlas, 1995.

FONSECA, E. N. A bibliografia como ciência: da crítica textual à bibliometria. $R$. bras. Bibliotecon. Doc., v. 12, n. 1-2, p. 23-28, jan./jun. 1979.

FREIRE, I. M. O olhar da consciência possível sobre o campo científico. Ciência da informação, Brasília, v.32, n.1, p.50-59, jan./abr. 2003.

GINZBURG, C. Sinais: raízes de um paradigma indiciário. In: Mitos, emblemas, sinais: morfologia e história. São Paulo: Cia. das Letras, 2003. p. $143-180$.

INFORMATION RESOURCE CENTER. Sport thesaurus 1987 edition: the thesaurus of terminology used in the Sport Database. Ontário: [s.n.], 1987.

MEADOWS, A. J. A Comunicação Científica. Brasília: Briquet de Lemos, 1999. 268p. 
SENGUPTA, J. N. Bibliometrics, infometrics, scientometrics and librametrics: an overview. Libri, International Journal of Libraries and Information Systems, Munique, v. 42, n.2, p. 75-98, 1992. 